\title{
Older LGBT+ Health Inequalities in the United Kingdom: Setting a Research Agenda
}

\author{
Sue Westwood ${ }^{1}$, Paul Willis ${ }^{2}$, Julie Fish ${ }^{3}$, Trish Hafford-Letchfield ${ }^{4}$, Joanna
}

Semlyen ${ }^{5}$, Andrew King ${ }^{6}$, Brian Beach ${ }^{7}$, Kathryn Almack ${ }^{8}$, Dylan Kneale ${ }^{9}$, Michael Toze $^{10}$ and Laia Becares ${ }^{11}$

Corresponding Author:

Dr Sue Westwood, York Law School, University of York, LMB/258, Law and Management Building, Freboys Lane, York, YO10 5GD, UK.

E-mail: sue.westwood@york.ac.uk

Word count: 1559 words

\footnotetext{
${ }^{1}$ York Law School, University of York, UK

${ }^{2}$ School for Policy Studies, University of Bristol, UK

${ }^{3}$ School of Applied Social Sciences, De Montfort University, UK

${ }^{4}$ School of Social Work \& Social Policy, University of Strathclyde, UK

${ }^{5}$ Norwich Medical School, University of East Anglia, UK

${ }^{6}$ Department of Sociology, University of Surrey, UK

${ }^{7}$ International Longevity Centre UK (ILC-UK)

${ }^{8}$ School of Health and Social Work, University of Hertfordshire, UK

${ }^{9}$ UCL Institute of Education, University College London

${ }^{10}$ Lincoln Medical School, University of Lincoln, UK

${ }^{11}$ Social Work and Social Care, Data Intensive Science Centre, University of Sussex, UK
} 


\title{
Older LGBT+ Health Inequalities in the United Kingdom: Setting a Research Agenda
}

\begin{abstract}
Lesbian, gay, bisexual and trans $+^{\mathrm{a}}(\mathrm{LGBT}+)$ people report poorer health than the general population and worse experiences of healthcare particularly cancer, palliative/end-of-life, dementia and mental health provision. This is attributable to: a) social inequalities, including 'minority stress'; b) associated health-risk behaviours (e.g. smoking, excessive drug/alcohol use, obesity); c) loneliness and isolation, affecting physical/mental health and mortality; d) anticipated/experienced discrimination and e) inadequate understandings of needs among healthcare providers. Older LGBT+ people are particularly affected, due to the effects of both cumulative disadvantage and ageing. There is a need for greater and more robust research data to support growing international and national government initiatives aimed at addressing these health inequalities. We identify seven key research strategies: 1) Production of large datasets; 2) Comparative data collection; 3) Addressing diversity and intersectionality among LGBT+ older people; 4) Investigation of healthcare services' capacity to deliver LGBT+ affirmative healthcare and associated education and training needs; 5) Identification of effective health promotion and/or treatment interventions for older LGBT+ people, and sub-groups within this umbrella category; 6) Development an (older) LGBT+ health equity model; 7) Utilisation of social justice concepts to ensure meaningful, change-orientated data production which will inform and support government policy, health promotion and healthcare interventions.
\end{abstract}

Key words: Health Inequalities; Social Determinants; sexual orientation; gender identity; ageing

\section{Introduction}

The United States (US) has led the way in establishing a lesbian, gay, bisexual and trans+ $(\mathrm{LGBT}+)^{\mathrm{a}}$ health inequalities research agenda ${ }^{[1]}$ but there is still much to be done worldwide. LGBT+ people report poorer health than the general population and worse experiences of healthcare particularly cancer ${ }^{[2]}$, palliative/end-of-life ${ }^{[3]}$, dementia ${ }^{[4]}$ and mental health provision. ${ }^{[5-6]}$ Their poorer health may be attributable to: a) social inequalities, including 'minority stress', ${ }^{[7]}$ i.e. the cumulative effects of lifelong exposure to prejudice and discrimination; b) health-risk behaviours (e.g. comparatively greater smoking, excessive drug/alcohol use and obesity than non-LGBT+ people) linked to stress adaptation; c) loneliness 
Journal Epidemiology and Community Health 2020 (in press)

and isolation, affecting physical/mental health and mortality. ${ }^{[8]}$ Healthcare experiences are associated with anticipated/experienced discrimination and inadequate understandings of needs among healthcare providers. ${ }^{[9]}$

In Europe, there is growing governmental interest in promoting an LGBT+ health inequalities research agenda, ${ }^{[10-11]}$ but no specific reference to older LGBT+ people (i.e. those aged $50+$ ). This is even though they are more likely to be users of healthcare services and there being a range of health inequalities specific to their lives. ${ }^{[12]}$ Indeed, older LGBT+ people are affected by both ageing issues common to all older people and issues specific to LGBT ageing. ${ }^{[13]}$

The generic ageing issues they share with all older people include ${ }^{[14]}$ : biological ageing 'associated with the gradual accumulation of a wide variety of molecular and cellular damage' leading to 'a gradual decrease in physiological reserves, an increased risk of many diseases, and a general decline in the capacity of the individual' ultimately resulting in death. Although more people are living for longer and into 'older' old age, many are doing so with increasing physical and/or cognitive abilities and associated functional challenges. These in turn mean that many may need support with activities of everyday living (ADLs), ${ }^{[15]}$ especially in older old age and may become reliant on others for informal and/or formal care and support. Many older people face living with unmet care and support needs. ${ }^{[16]}$ These issues affect older people in different ways and at different stages of ageing. A great many economic, cultural and psychosocial factors affect the extent to which an older person is able to age 'well' or not.

Older age also involves changes in social roles and social status, and the need to deal with the loss of (ageing) friends and loved-ones. ${ }^{[14]}$ Loneliness and isolation can be one of the perils of older age, impacting physical and mental wellbeing and ultimately morbidity. ${ }^{[17]}$ On the other hand, shifting motivations, priorities and psychological perspectives can also mean that older age can be a time of subjective well-being for many older people. ${ }^{[14]}$ 
Journal Epidemiology and Community Health 2020 (in press)

In addition to these generic ageing issues, older LGBT+ people are also affected by how their minority sexualities and/or gender identities intersect with ageing. They are more likely than the majority ageing population to live alone, to be childfree (especially older gay men), and estranged from their biological families. ${ }^{[18]}$ While many have 'families of friends ${ }^{\text {' }}{ }^{[19]}$ these are often of the same generation, developing increased care needs at the same time and being less able to provide reciprocal care. Older gay and bisexual men are deeply affected by HIV/AIDS, through loss of friends in previous decades and increasing numbers with HIV living longer on treatments. ${ }^{[20]}$ Older cisgender lesbian and bisexual women live longer than men, but with greater disabilities and age-related health conditions. ${ }^{[1]}$ Older trans+ people are concerned about the possible need for personal care if their bodies are not congruent with a binary gender identity and also of being mis-gendered if they lose mental capacity. ${ }^{[22]}$ Older LGBT+ people, especially older bisexual and trans+ people are more likely to have a history of poor mental health and to be concerned about mental health in older age. ${ }^{[12,18]}$

All of these concerns are nuanced by a wide range of intersecting factors, including socioeconomic status; culture, race and ethnicity; disability; and religion. ${ }^{[23]}$ Some older LGBT people are more successful than others in adapting and coping with ageing: those with strong psychological and social resources are likely to enjoy better health and practice more healthpromotion behaviours. ${ }^{[24]}$ However, the design of effective interventions to promote such positive adaptations is not yet well understood.

The aim of this paper is to stimulate debate about mapping the way forward for research and policy and to propose a European agenda.

\section{Setting a Research Agenda}

\section{Large scale data}

Public health agencies rely on mortality/morbidity data to measure health inequalities, shape policies, target interventions, and audit outcomes, including in relation to meeting statutory 
Journal Epidemiology and Community Health 2020 (in press)

equality duties. There is a lack of large-scale quantitative data on older LGBT+ health, partly due to a lack of monitoring for sexual orientation/gender identity in routine healthcare services data collection, which urgently needs to be addressed. Other solutions include ensuring LGBT+ health research is older-age inclusive and older age health research is LGBT+ inclusive. Secondary analysis of large-scale health survey datasets pooled from multiple separate datasets is also an emergent way of creating larger samples for analysis. ${ }^{[25]}$

\section{Comparative data}

Understanding older LGBT+ health inequalities compared with the majority population requires robust comparative data. Very few studies have produced such data. Older LGBT+ people should be included in research in sufficient numbers to allow meaningful analysis. This means ensuring that a proportionate and statistically significant number of LGBT+ people should be included in all ageing research, and a proportionate and statistically significant number of older people should be included in research with LGBT+ adults. Making this an essential funding requirement would ensure that this is factored in to all research projects.

\section{LGBT+ diversity and intersectionality}

There has been very little comparison of the differential health experiences among older LGBT+ sub-groups across interacting and intersecting social differences (e.g. age, gender, class, ethnicity). ${ }^{[25]}$ Studies which employ more purposive sampling would provide greater insights into both diversity and intersectionality. ${ }^{[26]}$ This would enable policy-makers, commissioners and providers to better direct health interventions towards specific LGBT+ subgroups.

\section{Improving access to healthcare services}

There is now a body of work identifying barriers and facilitators to older LGBT+ people accessing care and support services. However, less is understood about 'healthcare stereotype 
Journal Epidemiology and Community Health 2020 (in press)

threat [which] is the threat of being personally reduced to group stereotypes that commonly operate within the healthcare domain'. ${ }^{[27]}$ This is particularly in relation to older LGBT+ people ${ }^{9}$ who are known to avoid healthcare services dues to concerns about prejudice and discrimination. Increased knowledge could improve healthcare professional's competency and confidence, resource allocation, inclusion in healthcare education, and developing a standard/quality framework for training.

\section{Improving the quality of healthcare services}

Research is needed to determine whether/how healthcare services' policies, procedures and practices are LGBT+ inclusive, and to evaluates training/interventions which develop healthcare staff competencies. ${ }^{[28-29]}$ Specifically, healthcare staff should be able to:

- Understand older LGBT+ people's lives, histories and legal landmarks, and the health impacts of growing up under pathologizing and criminalising regimes;

- Understand how prior experiences of religious and/or medical 'cures' (often forcible) can inform older LGBT+ people's fears about engaging with medical services and/or faith-based healthcare staff;

- Understand and respect older LGBT+ people's relationship networks, including their 'families of friends', giving same-sex partners equal status and recognition as differentsex partners, and promoting LGBT+ community ties;

- Understand and respond sensitively to the personal care concerns of those older transwomen and transmen whose bodies may not align with their gender identity.

- Confidently challenge homophobia, biphobia and/or transphobia on the part of staff, other healthcare users, their families and friends.

\section{Improving health promotion interventions}

Few empirical studies have explored health promotion interventions for older LGBT+ people. ${ }^{[30]}$ It is essential to understand what works best for whom, under what circumstances, and also how allied service providers (e.g., housing/home care) can work inclusively to amplify what works well and promote older LGBT+ people's coping, health and wellbeing. This is 
Journal Epidemiology and Community Health 2020 (in press)

relevant for all minority groups. Issues to be considered specifically in relation to older LGBT+ people include investigating the following: promoting individual, social and community supports and coping strategies; delivering health promotion campaigns which do not assume heterosexuality/ cisgender identities and which explicitly include older LGBT+ people; delivering health promotion campaigns specifically targeted at older LGBT+ people, e.g. addressing sexual health among older gay men, screening for cervical cancer among older lesbians, screening for breast cancer among transmen and so on.

\section{Developing an (older) LGBT+ health equity model}

The World Health Organisation has developed a social justice framework for the interactions between social inequalities and health. Yet despite compelling evidence of LGBT+ health inequalities, this framework fails to include them. We support calls for the WHO to include both sexual orientation and gender identity as social determinants of health and in all analyses of social inequalities and health ${ }^{[31-32]}$ including in older age. Additionally, research should support the development of health equity models specific to older LGBT+ people. ${ }^{[33]}$

\section{Aiming for substantive social justice}

US, Canadian, Australian and European research, policymaking and healthcare delivery agendas have come a long way, as evidenced by the growing number of initiatives aimed at LGBT health inequalities. In order to achieve substantive social justice beyond a box-ticking exercise, we must produce meaningful research to support these agendas.

\section{Conclusion}

Inclusion of older LGBT+ people and their advocates is essential in developing this agenda. The provision of care and support to older LGBT+ people is a 'litmus test' ${ }^{[34]}$ for how well healthcare agencies deliver services to minority groups. This research agenda takes us one step closer towards passing that test. 
Journal Epidemiology and Community Health 2020 (in press)

\section{Notes}

a. Trans+ $(\mathrm{t}+)$ is an umbrella term to encompass individuals who identify as transgender, agender, gender fluid and/or non-binary

\section{Acknowledgment}

Our thanks to the anonymous reviewers who made some particularly helpful comments on an earlier draft of this article.

\section{Funding statement}

This article was funded by a University of York (UK) Research Priming grant, Feb 2019 - July 2019 Westwood, S., Fish, J., Willis, P., Birks, Y. Older LGBTQ Health and Care Inequalities in the UK - Developing a collaborative research network.

\section{Competing Interests}

There are no competing interests for any author

\section{Contributorship Statement}

This article is informed by extensive collaborative work involving all of the co-authors for a research grant application submitted to the Wellcome Trust, funded by a Research Pump Priming Award from the University of York (Principle Investigator: lead author Sue Westwood). The award supported a literature review and networking conference, the focus of which was older LGBT+ health inequalities in the UK. The co-authors each attended the conference and presented papers at it. The lead author then drafted the first version of the article submitted here. It was circulated to all of the co-authors, each of whom provided extensive feedback both generic and on issues specific to their areas of expertise. Subsequent drafts were re-circulated on multiple occasions, further feedback was provided by all of the co-authors, and the final draft (submitted) was approved by all authors.

The co-authors contributed as follows: 
Journal Epidemiology and Community Health 2020 (in press)

Dr Paul Willis: substantial contributions to the conception of the article and thematic analysis; feedback on drafting and re-drafting; final approval of the submitted article; agreed to be accountable for article content. Made a particular contribution about health and social care provision about which he has published extensively, e.g. Willis, P., Maegusuku-Hewett, T., Raithby, M., \& Miles, P. (2016). Swimming upstream: The provision of inclusive care to older lesbian, gay and bisexual (LGB) adults in residential and nursing environments in Wales. Ageing \& Society, 36(2), 282-306.

Professor Julie Fish: substantial contributions to the conception of the article and thematic analysis; feedback on drafting and re-drafting; final approval of the submitted article; agreed to be accountable for article content. Made a particular contribution about heteronormative healthcare about which she has published previously (e.g. Fish, J., \& Karban, K. (Eds.). (2015). LGBT health inequalities: International perspectives in social work. Policy Press.)

Professor Trish Hafford-Letchfield: substantial contributions to the conception of the article and thematic analysis; feedback on drafting and re-drafting; final approval of the submitted article; agreed to be accountable for article content. Made a particular contribution about staff training about which she has published extensively, e.g. Hafford-Letchfield, T., Simpson, P., Willis, P. B., \& Almack, K. (2018). Developing inclusive residential care for older lesbian, gay, bisexual and trans (LGBT) people: An evaluation of the Care Home Challenge action research project. Health \& social care in the community, 26(2), e312-e320.

Dr Joanna Semlyen: substantial contributions to the conception of the article and thematic analysis; feedback on drafting and re-drafting; final approval of the submitted article; agreed to be accountable for article content. Made a particular contribution in relation to mental wellbeing (she is a psychologist) and about secondary data analysis in LGBT+ health research about which she has published previously, e.g. Semlyen, J. (2017). Recording sexual orientation in 
Journal Epidemiology and Community Health 2020 (in press)

the UK: Pooling data for statistical power. American Journal of Public Health 107, 1215-1217, https://doi.org/10.2105/AJPH.2017.303910

Professor Andrew King: substantial contributions to the conception of the article and thematic analysis; feedback on drafting and re-drafting; final approval of the submitted article; agreed to be accountable for article content. Made a particular contribution about LGBT+ ageing about which he is a leading UK expert, having recently co-authored a 'state-of-the-art' review: Almack, K., \& King, A. (2019). Lesbian, Gay, Bisexual, and Trans Aging in a British Context: Discussion of State-of-the-Art Empirical Research. The International Journal of Aging and Human Development, 0091415019836921.

Dr Brian Beach: substantial contributions to the conception of the article and thematic analysis; feedback on drafting and re-drafting; final approval of the submitted article; agreed to be accountable for article content. Made a particular contribution about policy implications having recently authored a report on older LGBT+ health inequalities for the International Longevity Centre: Beach, B. (2019) Raising the equality flag: Health inequalities among older LGBT people in the UK. London: ILC-UK.

Professor Kathryn Almack: substantial contributions to the conception of the article and thematic analysis; feedback on drafting and re-drafting; final approval of the submitted article; agreed to be accountable for article content. Made a particular contribution about both LGBT+ end of life carer and LGBT+ ageing about which she is a leading UK expert, having recently co-authored a 'state-of-the-art' review: Almack, K., \& King, A. (2019). Lesbian, Gay, Bisexual, and Trans Aging in a British Context: Discussion of State-of-the-Art Empirical Research. The International Journal of Aging and Human Development, 0091415019836921

Dr Dylan Kneale: substantial contributions to the conception of the article and thematic analysis; feedback on drafting and re-drafting; final approval of the submitted article; agreed to be accountable for article content. Made a particular contribution about methodology having 
Journal Epidemiology and Community Health 2020 (in press)

recently led a UK systematic literature review: Kneale, D., Henley, J., Thomas, J., \& French, R. (2019). Inequalities in older LGBT people's health and care needs in the United Kingdom: a systematic scoping review. Ageing \& Society, 1-23, doi:10.1017/S0144686X19001326

Dr Michael Toze: substantial contributions to the conception of the article and thematic analysis; feedback on drafting and re-drafting; final approval of the submitted article; agreed to be accountable for article content. Made a particular contribution in relation to older transgender health issues, on which his $\mathrm{PhD}$ was based, and in which field he is an emerging scholar, e.g. Toze, M. (2019). Developing a critical trans gerontology. The British Journal of Sociology, 70(4), 1490-1509.

Dr Laia Becares: substantial contributions to the conception of the article and thematic analysis; feedback on drafting and re-drafting; final approval of the submitted article; agreed to be accountable for article content. Make a particular contribution in relation to gender and health inequalities research, about which she has previously published, e.g. Bécares, L. and Zhang, N. (2017) Perceived interpersonal discrimination and older women's mental health: accumulation across domains, attributions, and time. American Journal of Epidemiology, 187 (5), 924-932.

\section{References}

1. Meyer, I. H., \& Northridge, M. E. (Eds.). (2007). The health of sexual minorities: Public health perspectives on lesbian, gay, bisexual and transgender populations. Springer.

2. Fish, J., \& Williamson, I. (2018). Exploring lesbian, gay and bisexual patients' accounts of their experiences of cancer care in the UK. European Journal of Cancer Care, 27(1), e12501.

3. Almack, K. (2016). Dying, Death and Bereavement. In Goldberg, A (ed) The SAGE Encyclopaedia of LGBTQ Studies. New York: Sage, 342-347 
Journal Epidemiology and Community Health 2020 (in press)

4. Westwood, S., \& Price, E. (Eds.). (2016). Lesbian, gay, bisexual and trans* individuals living with dementia: Concepts, practice and rights. Routledge.

5. Semlyen, J., et al. (2016). Sexual orientation and symptoms of common mental disorder or low wellbeing: combined meta-analysis of $12 \mathrm{UK}$ population health surveys. BMC Psychiatry, 16(1), 67.

6. Ellis, S. J., Bailey, L., \& McNeil, J. (2015). Trans people's experiences of mental health and gender identity services: A UK study. Journal of Gay \& Lesbian Mental Health, 19(1), 4-20.

7. Frost, D.M. Lehavot, K. Meyer, I.H. (2015) Minority stress and physical health among sexual minority individuals. Journal of Behavioural Medicine, 38, 1-8.

8. Fish, J. and Weis, C. (in press) All the lonely people, where do they all belong? An interpretive synthesis of loneliness and social support in older lesbian, gay and bisexual communities. Quality in Ageing and Older Adults. doi:10.1108/QAOA-10-2018-0050

9. Fredriksen-Goldsen, K. I., Hoy-Ellis, C. P., Goldsen, J., Emlet, C. A., \& Hooyman, N. R. (2014). Creating a vision for the future: Key competencies and strategies for culturally competent practice with lesbian, gay, bisexual, and transgender (LGBT) older adults in the health and human services. Journal of gerontological social work, 57(2-4), 80-107.

10. Government Equalities Office (2018) LGBT Action Plan 2018: Improving the lives of Lesbian, Gay, Bisexual and Transgender people. London: HMSO

11. European Union (EU) (2017) Health4LGBTI: State-of-the-Art Synthesis Report Brussels: EU.

12. Kneale, D. et al (frth) Inequalities in older LGBT people's health and care needs in the UK: A systematic scoping review. Ageing and Society 
Journal Epidemiology and Community Health 2020 (in press)

13. Westwood, S. (2016). Ageing, Gender and Sexuality: Equality in Later Life. Abingdon: Routledge

14. World Health Organization. (2015). World Report on Ageing and Health. World Health Organization. Page 25.

15. Quinn, T. J., McArthur, K., Ellis, G., \& Stott, D. J. (2011). Functional assessment in older people. Bmj, 343, d4681.

16. Vlachantoni, A., Shaw, R. J., Evandrou, M., \& Falkingham, J. (2015). The determinants of receiving social care in later life in England. Ageing \& Society, 35(2), 321-345.

17. Luo, Y., Hawkley, L. C., Waite, L. J., \& Cacioppo, J. T. (2012). Loneliness, health, and mortality in old age: A national longitudinal study. Social science \& medicine, 74(6), 907914.

18. Guasp, A. (2011). Lesbian, Gay and Bisexual People in Later Life. London: Stonewall.

19. Westwood, S. (2013). 'My Friends are my Family': an argument about the limitations of contemporary law's recognition of relationships in later life. Journal of Social Welfare and Family Law, 35(3), 347-363.

20. Lyons, A., Pitts, M., Grierson, J., Thorpe, R., \& Power, J. (2010). Ageing with HIV: health and psychosocial well-being of older gay men. AIDS care, 22(10), 1236-1244.

21. Westwood, S. (2016). Dementia, women and sexuality: How the intersection of ageing, gender and sexuality magnify dementia concerns among lesbian and bisexual women. Dementia, 15(6), 1494-1514.

22. Hunter, C., Bishop, J. A., \& Westwood, S. (2016). The complexity of trans*/gender identities: Implications for dementia care. In S. Westwood and E. Price (eds) Lesbian, Gay, Bisexual and Trans* Individuals Living with Dementia: Concepts, Practice and Rights, pp. 124-137. Abingdon: Routledge. 
Journal Epidemiology and Community Health 2020 (in press)

23. King, A., \& Almack, K. (Eds.). (2019). Intersections of ageing, gender, sexualities: Multidisciplinary international perspectives. Policy Press.

24. Fredriksen-Goldsen, K. I., et al (2017). The cascading effects of marginalization and pathways of resilience in attaining good health among LGBT older adults. The Gerontologist, 57(suppl_1), S72-S83

25. Semlyen, J. (2017). Recording sexual orientation in the UK: Pooling data for statistical power. American Journal of Public Health 107 (8):1215-7

26. Klar, S., \& Leeper, T. J. (2019). Identities and Intersectionality: A Case for Purposive Sampling in Survey-Experimental Research. Experimental Methods in Survey Research, 419-433.

27. Abdou, C. M., Fingerhut, A. W., Jackson, J. S., \& Wheaton, F. (2016). Healthcare stereotype threat in older adults in the Health and Retirement Study. American Journal of Preventive Medicine, 50(2), 191-198, page 191.

28. Porter, K. E., \& Krinsky, L. (2014). Do LGBT aging trainings effectuate positive change in mainstream elder service providers?. Journal of homosexuality, 61(1), 197-216.

29. Hafford-Letchfield, T., Simpson, P., Willis, P. B., \& Almack, K. (2018). Developing inclusive residential care for older lesbian, gay, bisexual and trans (LGBT) people: An evaluation of the Care Home Challenge action research project. Health \& social care in the community, 26(2), e312-e320.

30. Fish, J. et al (2016) Equality in sexual health promotion: a systematic review of effective interventions for black and minority ethnic men who have sex with men. BMC Public Health, 16:810 
Journal Epidemiology and Community Health 2020 (in press)

31. Logie, C. (2012). The case for the World Health Organization's Commission on the Social Determinants of Health to address sexual orientation. American Journal of Public Health, 102(7), 1243-1246.

32. Pega, F., \& Veale, J. F. (2015). The case for the World Health Organization's Commission on Social Determinants of Health to address gender identity. American Journal of Public Health, 105(3), e58-e62

33. Fredriksen-Goldsen, K. I., et al. (2014). The health equity promotion model: Reconceptualization of lesbian, gay, bisexual, and transgender (LGBT) health disparities. American Journal of Orthopsychiatry, 84(6), 653.

34. Ward, R., Pugh, S., \& Price, E. (2010). Don't look back?: Improving health and social care service delivery for older LGB users. Manchester: Equality and Human Rights Commission. 
Journal Epidemiology and Community Health 2020 (in press)

\section{SUMMARY BOX}

What is already known on this subject?

LGBT+ people report poorer health than the general population and worse experiences of healthcare particularly cancer, palliative/end-of-life, dementia and mental health provision. This is attributable to: a) social inequalities, including 'minority stress'; b) associated healthrisk behaviours (e.g. smoking, excessive drug/alcohol use, obesity); c) loneliness and isolation, affecting physical/mental health and mortality; d) anticipated/experienced discrimination and inadequate understandings of needs among healthcare providers. Older LGBT+ people are particularly affected, due to the effects of both cumulative disadvantage and ageing. There is a need for greater and more robust research data to support growing international and national government initiatives aimed at addressing these health inequalities.

What this study adds

We identify seven key research strategies: 1) Production of large datasets; 2) Routine inclusion of LGBT+ people in ageing research and older people in LGBT+ research; 3) Exploration of diversity and intersectionality among cohorts of LGBT+ older people; 4) Investigation of healthcare services' capacity to deliver LGBT + affirmative healthcare and associated education and training needs; 5) Identification of effective health promotion and/or treatment interventions for older LGBT+ people, and sub-groups within this umbrella category; 6) Development an (older) LGBT+ health equity model; 7) Utilisation of social justice concepts to ensure meaningful, change-orientated data production which will inform and support government policy, health promotion and healthcare interventions. 